\title{
O sentido da relação trabalho e saúde para os assistentes em administração de uma universidade pública federal no Estado de Minas Gerais
}

\author{
I ${ }^{1}$ Renata Mercês Oliveira de Faria, ${ }^{2}$ Isabel Cristina Gonçalves Leite, \\ ${ }^{3}$ Girlene Alves da Silva I
}

Resumo: O objetivo deste estudo foi analisar o sentido da relação trabalho e saúde para os assistentes em administração de uma instituição pública de ensino superior no Estado de Minas Gerais. O trabalhador do setor público é considerado privilegiado por ter emprego estável, como se também não estivesse submetido a condiçōes de trabalho que levam ao sofrimento e adoecimento. Para aproximação desse universo, na presente pesquisa de cunho qualitativo, adotou-se a técnica de grupo focal, e as informaçôes coletadas foram interpretadas à luz da análise de conteúdo. Como resultados, destacamos a importância das relaçōes interpessoais, da transparência e participação na gestão e do reconhecimento através da valorização dos esforços dos trabalhadores para resolver os problemas. O engajamento no trabalho foi outra característica marcante e distancia-se da visão difundida socialmente do servidor público. A limitação do poder de ação no desenvolvimento das atividades e a falta de comunicação entre os setores prejudicam os processos de trabalho, já que não se conclui o serviço da maneira desejada. Tais elementos devem tornar-se foco no processo de vigilância da relação trabalho e saúde, como estratégicos na organização social dos ambientes de trabalho no sentido de ampliação da saúde institucional e da qualidade dos serviços prestados.

> Palavras-chave: saúde do trabalhador; setor público; condições de trabalho.

\author{
1 Universidade Federal de Juiz \\ de Fora. Juiz de Fora-MG, Brasi \\ (renata.faria@ufjf.edu.br). \\ 2 Universidade Federal de Juiz \\ de Fora. Juiz de Fora-MG, Brasil \\ (isabel.leite@ufjf.edu.br). \\ ${ }^{3}$ Universidade Federal de Juiz \\ de Fora. Juiz de Fora-MG, Brasil \\ (girleneas@terra.com.br).
}

Recebido em: 20/10/2016 Aprovado em: 30/05/2017 


\section{Introdução}

O trabalho possui centralidade na vida social dos homens. Essa afirmativa pode parecer paradoxal em meio ao contexto de globalização, neoliberalismo e adoção de políticas como privatizações e redução do papel do Estado como agente regulador da economia. Contemporaneamente, muito se discute se ele ocupa lugar de destaque nas relações sociais mediante tantas mudanças ocorridas. Afina-se aqui, portanto, com a visão proposta por Antunes (2013) de que o trabalho continua sendo um eixo estruturante do viver em sociedade.

Neste artigo, pretende-se abordar o contexto do trabalho delimitado pelo setor público, mais especificamente de uma instituição de ensino superior, sendo sua produção algo de valor inestimável: a educação. Esse processo de trabalho que gera conhecimentos, essencial para o desenvolvimento de uma sociedade, encontra-se no setor de serviços, no qual o resultado do trabalho não possui materialidade, não é um produto físico, mas fornece as condições e os pressupostos institucionais e culturais necessários para a manutenção da produtividade (NOGUEIRA; ROSSINI, 2007).

As universidades públicas possuem por definição uma tríade que representa sua função-fim: ensino, pesquisa e extensão. Para atender a esses objetivos, são necessários servidores docentes e técnicos administrativos; esses últimos, responsáveis pela administração e por serviços de apoio. Destaca-se a visão de Coutinho et al. (2008), para quem, aos técnicos administrativos, por serem executores das atividades-meio, muitas vezes, não é dada atenção prioritária nas políticas públicas e internas das instituições de educação.

Os serviços da área-meio não possuem caráter de produção, mas de apoio, têm pouca visibilidade social e, frequentemente, dependem de uma cadeia de serviços que se entrelaçam para serem concluídos (CODO, 2002). Vislumbrase, no entanto, uma inserção vinculada ao processo educativo de forma ampla, através da atuação dos técnicos de forma integrada com a missão da universidade, sendo enriquecedor para todos os envolvidos: alunos, técnicos, professores e toda a comunidade externa assistida.

É nesse contexto que se pretende compreender as repercussões subjetivas da inserção dos técnicos no âmbito de uma universidade pública através da seguinte pergunta norteadora do presente estudo: qual o sentido do trabalho para os assistentes em administração e a sua relação com a saúde? 
Adota-se aqui a relação trabalho e saúde em perspectiva ampla, não como mera

ausência de doenças, sob o olhar individualizante e medicalizante dela. Vinculase, portanto, tal relação a condições multifacetadas e destacam-se entre elas as sócio-históricas, em que o processo de trabalho é visto como importante fator na gênese das insatisfaçôes e dos adoecimentos (GOMEZ, 2011; LAURELL; NORIEGA, 1989). A proposta aqui é ir além dos dados quantitativos vinculados aos diagnósticos das doenças que acometem os servidores em questão.

O trabalhador do setor público é estigmatizado, sendo considerado privilegiado por ter um emprego estável, como se também não estivesse submetido a condições de trabalho que podem levar ao sofrimento e adoecimento (CARNEIRO, 2006; WALLACE; LEMAIRE; GHALI, 2009). Ainda são poucas as pesquisas que se preocupam com o conteúdo simbólico do trabalho, com seus aspectos invisíveis, com as relações subjetivas do trabalhador com sua atividade (LANCMAN; SNELWAR, 2011).

É em meio a tais descompassos que se buscou analisar o sentido da relação trabalho e saúde para os técnicos administrativos em educação, com cargos de assistentes em administração de uma instituição pública de ensino superior no Estado de Minas Gerais.

\section{Métodos}

O público-alvo deste estudo são os servidores ocupantes do cargo de assistente em administração de uma instituição pública de ensino superior no Estado de Minas Gerais. Esse é o cargo que possui o maior número de técnicos administrativos em educação, totalizando $424(32,8 \%)^{1}$. A atuação deles acontece em unidades acadêmicas e administrativas e representa a diversidade dos ambientes de trabalho dessa instituição.

O cargo de assistente em administração é uma função na qual a exigência de escolaridade é o ensino médio, completo ou profissionalizante. As atividades deste cargo concentram-se em dar suporte administrativo e técnico nas diferentes áreas da universidade e, inclusive, assessorar nas atividades de ensino, pesquisa e extensão (BRASIL, 2005).

As relações entre a deterioração da saúde e o trabalho revestem-se de uma grande complexidade na qual, muitas vezes, os sinais reveladores de sofrimento não são passíveis de ser classificados em diagnósticos tradicionais, ocultando, 
assim, os efeitos do trabalho na saúde. A pesquisa realizada, de cunho qualitativo, foi escolhida pela possibilidade de aproximação deste universo, através da escuta dos servidores.

$\mathrm{O}$ uso de depoimentos tem por objetivo reunir discursos em que os sujeitos contam sua história, reunindo informaçōes sobre a realidade vivida no trabalho: o indivíduo é testemunha de seu tempo, de seu ambiente e de sua inserção social (MINAYO, 1994).

Para a apreensão das informações, foi aplicada a técnica de grupo focal, ao propiciar um debate aberto e acessível, permitindo que os temas abordados sejam mais problematizados que numa situação de entrevista individual. A utilização dessa técnica de pesquisa, inclusive, tem sido crescente no campo da Saúde Coletiva no Brasil (GONDIM, 2002; TRAD, 2009).

O convite para participação da pesquisa foi feito através de contato pessoal com cada assistente em administração, no próprio ambiente de trabalho. Dessa forma, foram realizadas visitas em todos os setores administrativos e acadêmicos da universidade.

Foram realizadas 11 reunióes com diferentes grupos de participantes, adotando-se a técnica de "grupo focal" (TRAD, 2009) como principal instrumento de coleta de dados. Participaram 53 integrantes, com média de cinco participantes por grupo. Os grupos foram organizados de acordo com a inserção dos assistentes em administração em unidades acadêmicas (Faculdades e Institutos) ou administrativas (Pró-Reitorias), no sentido de propiciar troca de experiências comuns. Houve a representatividade dos diferentes ambientes de trabalho, o que possibilitou a abrangência do objeto de estudo investigado em suas múltiplas dimensões (MINAYO, 1994).

As informações coletadas foram interpretadas à luz da análise de conteúdo (BARDIN, 2011), composta pela categorização dos temas na busca de diversidade de significados de singularidades. A reincidência de informação sobre o universo abordado orientou o encerramento da coleta de dados.

O estudo foi conduzido dentro dos padrões éticos e aprovado pelo Comitê de Ética em Pesquisa da instituição estudada, sob o Parecer n. 998.906. Os depoimentos dos participantes foram apresentados de forma a resguardar suas identidades. A identificação em cada depoimento qualifica o participante da seguinte forma: P, de participante, letras do alfabeto para diferenciar cada 
participante, seguido do número do grupo, por ordem de realização; letra $\mathrm{F}$ ou

$\mathrm{M}$ para feminino ou masculino e número indicativo de tempo de atuação em anos na instituição.

Dos 53 participantes do estudo, 68\% são do sexo feminino, idade média de 44,17, variando entre 22 e 67 anos. O tempo médio de trabalho na universidade é 16,22 anos, compreendendo de um a 37 anos de trabalho na universidade. Embora a exigência do cargo seja nível médio completo, somente $8 \%$ possuem essa formação, $36 \%$ possuem nível superior completo e os outros $56 \%$ têm pós-graduação.

\section{Resultados e Discussão}

As categorias identificadas para esse grupo estudado trouxeram à tona os elementos que interferem na relação trabalho e saúde. $\mathrm{O}$ trabalho aparece em toda a sua complexidade, como fonte de saúde e também de adoecimento, como um eixo estruturante da vida social, como possibilidade de conjugar estabilidade financeira e qualidade de vida, sendo este equilíbrio associado à condição de servidor público.

\section{Relação trabalho e saúde-doença}

O trabalho é o vínculo material e o objetivo entre ser humano e natureza. Por esse motivo, é a categoria fundante e mediadora por excelência, assinalando a passagem do ser meramente biológico ao ser social (LUKÁCS, 2013). Desempenha papel importante na organização da vida dos trabalhadores ao ser associado com crescimento pessoal, familiar, social e financeiro (ERLANDSSON et al., 2012).

O valor do trabalho como fonte de saúde pode ser identificado nas seguintes falas:

O trabalho é tudo para o ser humano... aquela música fala o homem sem trabalho, se morre, se mata, não dá pra ser feliz... Você sai de casa para trabalhar e ele é a sua vida. Nele é que você resolve tudo... na verdade o trabalho é a fonte da saúde [...] (PA1M32).

A minha experiência dentro do trabalho é que ele só soma, só me ajuda a manter uma qualidade de vida e isso reflete na minha saúde em todos sentidos... traz saúde, prazer, satisfação, ah... não estou ganhando rios de dinheiro, mas estou feliz, no final das contas é isso aí: sou muito feliz! (PA4M2). 
A relação subjetiva com o trabalho vai além do espaço institucional. A separação clássica entre dentro e fora do trabalho não tem sentido quando nos referimos à dinâmica dos processos psíquicos e sociais (LANCMAN; SNELWAR, 2011). A declaração seguinte aponta para a amplitude do espaço de trabalho na vida social:

[...] trabalhar... não tem uma blindagem, não sai e larga aquilo ali definitivamente. A gente até não leva tudo pra casa, mas uma boa parte você leva e conforme as coisas acontecem ali as suas relaçôes do lado de fora são melhores ou piores e as relaçôes sociais têm um reflexo direto na saúde da gente como um todo, sem dúvida né [...] (PB7F6).

É nesse sentido que o trabalho permanece sendo uma fonte de pesquisa de importância capital. A centralidade do trabalho é percebida na construção da identidade, na realização de si mesmo e na saúde mental. O trabalho é um gerador de saúde, ou, ao contrário, um constrangimento patogênico, que pode contribuir para desestabilização e descompensação do sujeito (DEJOURS; ABDOUCHELI; JAYET, 2014), como pode ser verificado no depoimento a seguir:

[...] você vai alimentando um instinto que eu não sei onde ele vai chegar entendeu, de coisas que você não consegue resolver... você está falando para as paredes... isto afeta a saúde [...] (PC3F25).

Através das experiências trazidas, percebem-se sentimentos diversos que oscilam entre sofrimento e prazer. O prazer, associado à qualidade de vida e ao bem-estar no trabalho, e, por outro lado, o sofrimento, que aparece associado a experiências marcadas pela indiferença, falta de escuta, desvalorização, desmotivação.

Neste complexo processo de trabalho, destacam-se elementos que potencializam o sentido da relação trabalho e saúde para esse grupo, como: as relaçôes interpessoais, a gestão participativa e o engajamento e reconhecimento no trabalho. Essa descoberta, embora para um grupo específico, está em sintonia com resultados de outros estudos que apontam para a influência dos aspectos qualitativos vinculados à organização do trabalho (BIANCHESSI; TITTONI, 2009; FERREIRA, 2012; MATTOS; LUZ, 2012; NEGELISKII; LAUTERT, 2011; ROCHA; SOUZA; TEIXEIRA, 2015; SILVA; MOREIRA, 2015). É dentro dessa abordagem que se evidencia a relação entre saúde e a atividade de trabalho (CLOT, 2010), à medida que os trabalhadores possam verdadeiramente se reconhecer naquilo que fazem. 
Neste estudo, foi identificado que os relacionamentos entre os sujeitos desempenham papel importante na relação trabalho e saúde e podem ser fontes tanto de sofrimento quanto de resiliência (LEÃO; GOMEZ, 2014; NEGELISKII; LAUTERT, 2011).

A fala seguinte traz o polo do bem-estar produzido pelo apoio do grupo no processo de trabalho, as relações de coleguismo e amizade construídas e como colaboram para a sensação de satisfação nos ambientes de trabalho.

[...] eu acho que a melhor parte do trabalho são os colegas que a gente faz, os amigos que a gente faz, eu acho que a gente consegue dar conta de tudo que vem justamente porque um dá suporte para o outro, a melhor parte somos nós que fazemos [...] (PA2M7).

Um dos entrevistados, inclusive, aponta que o bom relacionamento ameniza outras situações não tão agradáveis, como a realização de tarefas identificadas como repetitivas e burocráticas:

[...] eu tenho que lançar pagamento... é a mesma coisa sempre... mas as outras coisas compensam: o ambiente de trabalho, a sensação de cooperativismo entendeu... o ambiente de trabalho me satisfaz às vezes no que o serviço burocrático me oprime um pouco $[\ldots]$ (PD3F2).

O depoimento a seguir traduz como essas relações trazem percepções diferenciadas a ponto de gerarem uma experiência na qual são identificadas duas universidades diferentes:

[...] no meu antigo setor não cheguei a ficar doente, mas essa sensação de pertencimento eu só vim a ter no meu novo ambiente de trabalho... acho que a questão da cordialidade entre os colegas, a questão de amizade, as relações interpessoais interferem muito nisso para você se sentir pertencente, se sentir realizado, eu vim sentir isso agora... é como se existissem duas universidades, como se não fosse a mesma instituição por causa da relação interpessoal [...] (PB6M4).

As relações interpessoais, além de trazer percepções diferenciadas, provocam inclusive adoecimento:

[...] eu tive muitos problemas dessa relação e entrei até em crise de depressão, pânico e tudo mais... eu acho que no ambiente de trabalho quando ocorre esse tipo de problema, deveria ter um suporte dentro do setor, com aqueles que não estão se entendendo, acho que a gente não deve ir só lá procurar uma junta médica (PA6F31).

Percebe-se nesse depoimento visão ampliada da necessidade de se desenvolver a saúde no ambiente de trabalho, desvinculando o adoecimento restrito a uma perspectiva individual, sob a ótica médica. 
Identificou-se ainda que as relações interpessoais possuem um peso importante para os servidores, tanto para os novatos como para os mais antigos. Essa é outra marca do serviço público, pois nele é possível cultivar amizades e bons relacionamentos pela possibilidade de uma carreira contínua e de trabalhos conjuntos, em um contexto mundial de precarização do trabalho.

No relato a seguir, identifica-se a possibilidade de aprendizagem contínua através da relação com o outro, do lidar com os diferentes, em vez da lógica de descartabilidade característica intrínseca do capitalismo e respectivo consumismo (NASCIMENTO; OLIVEIRA, 2013; SENNETT, 2007; SPILKI; TITTONI, 2005). Esta relação com o outro, portanto, possibilita crescimento pessoal e saúde:

[...] eu comecei a aprender o que eu podia pedir pra quem... eu sei que o fulano atende super bem as pessoas, mas não adianta pedir para ele uma planilha no computador, o outro vai fazer todas as planilhas do mundo, mas não adianta pedir para secretariar uma reunião... o que cada um tinha de melhor pra contribuir... e eu acabei crescendo até como pessoa... e isto é uma forma de você ter saúde! (PD8F21).

A relação com a tarefa implica fundamentalmente o relacionamento com os colegas, com o outro; o trabalhador está inteiramente tomado pela interação simbólica (LANCMAN; SZNELWAR, 2011). O apoio social no ambiente de trabalho foi vinculado neste estudo como fonte de bem-estar, prazer, vontade de ir para o trabalho e, inclusive, suporte para enfrentar as dificuldades impostas pelas tarefas burocráticas e repetitivas.

Dessa maneira, fica evidente que o trabalho e as relações que nele se originam nunca podem ser tomados como espaço de neutralidade subjetiva ou social (ARBEX; SOUZA; MENDONÇA, 2013).

As redes de cooperação e os pactos de solidariedade são cruciais para viabilizar os objetivos das tarefas e os desempenhos esperados e evitar os impactos negativos para a saúde individual e coletiva (FERREIRA, 2012; TJULIN et al., 2011). Outro elemento essencial para que ocorra a cooperação é a relação de confiança entre os colegas, chefes e dirigentes através de espaços de diálogo e construção coletiva (HIGGINS; O'HALLORAN; PORTER, 2015). Este foi outro ponto importante destacado pelos servidores em questão: a gestão participativa. Se sentir parte do processo produtivo, ser escutado, propor soluções, inovar, tudo isso potencializa a relação trabalho e saúde. 


\section{Gestão participativa como fonte de saúde}

A cultura institucional de uma universidade pública é fortemente participativa, não diretamente no processo de trabalho, mas de uma forma política, através da eleição de representantes como reitor e vice-reitor, que envolve a participação dos três segmentos que integram a universidade: alunos, funcionários e professores. $\mathrm{Na}$ composição de conselhos e comissões, busca-se também a representatividade dessas pessoas. Estes são os espaços de diálogo, de discussão e de aprovação de resoluções norteadoras do funcionamento da universidade.

Identificou-se neste estudo que a gestão participativa afeta a saúde em sentido amplo ao propiciar, inclusive, saúde institucional através da forma colegiada de decisão, através da participação de todos os envolvidos no processo de trabalho (BALTZER et al., 2011).

Com relação à execução das atividades nos ambientes de trabalho, verificouse que se sentir parte do processo produtivo potencializa o envolvimento no trabalho, através da possibilidade de inovar, imprimir sua identidade, apesar das regras e normas do ofício em questão:

[...] apesar do nosso trabalho ser mais generalista e envolver um pouco de burocracia, no nosso setor, a forma de gestão participativa proporciona você opinar, discutir, discordar... você se sente assim... estou mudando, estou produzindo algo diferente... não é assim: o manual diz isto, então vamos seguir isto aqui! O manual diz isto: a gente discute, eu tenho que melhorar [...] (PA4M2).

A questão da política no âmbito do setor público, no entanto, reforça a fragmentação da ação do servidor que, se por um lado zela pelo seu ofício e realiza as atividades inerentes ao seu cargo, por outro, sente-se perdido e isolado das decisões tomadas um andar acima da hierarquia. Muitas vezes, então, o que reina é a "política do não fazer" mediante um desenrolar de ações nas quais os servidores participam de forma desintegrada e distante (CODO, 2002).

O conceito de impedimento se materializa quando o sujeito não tem outra escolha senão a de restringir ou paralisar a ação, o que gera sofrimento e esvazia o sentido do trabalho (CHIAVEGATO FILHO, 2015).

A interferência negativa da política no processo de gestão do trabalho também aparece no relato, como a seguir:

[...] porque o que eu vejo na universidade não importa o que é trabalho, importa se você faz parte de uma política, ou melhor, se politicamente for mais importante tirar a mesa daqui do que tecnicamente... Essa mesa vai sair daqui, não quer saber quem vai usar, entendeu? (PC3F25). 
Se, por um lado, os servidores têm voz ativa nos processos de decisão, por outro, foi verificada pouca margem de ação, o que provoca uma limitação ao "poder de agir" (CLOT, 2010), colocando em risco a saúde ou levando ao “desengajamento” daqueles (JACKSON FILHO, 2015).

[...] muita coisa tá mudando, só que essas mudanças na maioria das vezes, elas não chegam na base, a gente só vai ficar sabendo da mudança quando o negócio impactou totalmente (PE1F4).

Quando os trabalhadores se encontram impedidos de agir, o risco para a saúde é evidente, pois o sofrimento que decorre das atividades impedidas interfere na liberdade de agir, sendo um ataque à integridade de si (CLOT, 2010).

É nesse contexto que se apresentam as repercussōes subjetivas da inserção dos técnicos na cadeia produtiva da universidade, como os desgastes gerados no processo de trabalho, verificado no seguinte relato:

[...] isto traz prejuízo pra gente, com certeza... a gente querer fazer e não conseguir concluir o trabalho... o pesar da gente é não dar o retorno tão rápido quanto a gente gostaria... a gente trabalha, mas não vê a coisa evoluir (PE2F22).

$\mathrm{Na}$ fala seguinte, identifica-se, inclusive, a importância da comunicação intersetorial para o bom andamento do trabalho:

[...] a relação do nosso setor com outros setores, é nesse ponto que eu acho complicado... a gente tem uma cadeia e tem coisa que você está fazendo que você sabia que podia ser diferente, que podia ser mais simples para o requisitante... essa falta de compromisso... isso que adoece [...] (PC3F25).

\section{Engajamento, reconhecimento e pertencimento no trabalho}

No campo da psicossociologia do trabalho (LHUILIER, 2014), o conceito e o objeto engajamento são considerados benéficos para os trabalhadores, ou seja, levam ao bem-estar, uma vez que se considera que trabalhar motivado por fatores ou valores nos quais se acredita faz bem (FAN et al., 2016; JACKSON FILHO, 2015).

Neste estudo, destacaram-se atitudes dos assistentes em administração, como: envolvimento, compromisso, apropriação, sentir-se útil, entre outras que podem ser incluídas na expressão engajamento. Apesar de estudos (CODO, 2002; COUTINHO; DIOGO; JOAQUIM, 2008; NUNES; LINS, 2009) apontarem a fragmentação dos executores das atividades administrativas em relação ao todo 
produtivo, perdendo de vista a missão institucional, os relatos seguintes mostram o compromisso com a formação dos alunos:

[...] por isso que eu me preocupo muito com os bolsistas, eu tenho que tratá- los da melhor forma, que eles consigam ter uma vida acadêmica proveitosa, o rendimento acadêmico do aluno seja mantido ou melhore [...] (PD4M7).

$\mathrm{Na}$ fala a seguir, notam-se o envolvimento e o pertencimento através da valorização do trabalho técnico do assistente em administração como garantia de continuidade do trabalho:

[...] eu criei raízes, sim, porque eu amo o meu trabalho, eu quero que o meu setor de trabalho cresça e que permaneça firme... o negócio de ser público parece que não é de ninguém... o diretor está indo embora e é agora que o meu setor precisa mais de mim, porque, o próximo que vai entrar, eu vou ensinar tudo pra ele [...] (PB2F25).

O engajamento demonstrado remete a uma atividade geradora de saúde, porque o trabalhador se reconhece naquilo que faz, com toda sua singularidade.

$\mathrm{O}$ processo dinâmico da atividade profissional exige a disponibilidade da iniciativa, da inventividade, da criatividade e de formas de inteligência específicas próximas daquilo que o senso comum classifica como engenhosidade (DEJOURS, 2011; MACHE et al., 2014; SILVA; RAMMINGER, 2014). O depoimento a seguir traz este importante traço no processo de trabalho que é a criação do novo:

[...] a partir do momento em que eu me apropriei do que eu faço, eu consigo ter um olhar crítico: no que eu posso melhorar? O que posso produzir mais? Eu acho que esta apropriação é extremamente importante para isso, para você melhorar e poder propor novos caminhos [...] (PC5M2).

Esta situação de protagonista está ligada às ações no campo da saúde do trabalhador (TITTONI, 2004), em que, através das próprias vivências, produzemse as possíveis análises e reflexões capazes de promover transformações. Neste caso, o próprio trabalhador pode reconhecer-se sujeito e ator de transformações possíveis (BIANCHESSI; TITTONI, 2009).

Além da retribuição material pela dedicação, verificou-se que a retribuição simbólica contribui favoravelmente para a relação trabalho e saúde, através do reconhecimento. Toda atividade de trabalho, portanto, inclui uma forte mobilização subjetiva, que, se por um lado é "espontânea", por outro, não deixa de ser extremamente frágil, dependendo da dinâmica entre contribuição e retribuição, envolvendo o julgamento de outrem. $\mathrm{O}$ trabalhador espera 
reconhecimento simbólico da sua contribuição, sem o qual tende a desmobilizarse, com profundas consequências para sua saúde mental. Pesquisas mostram que a dimensão simbólica constitui a parte mais importante e negligenciada da retribuição (DEJOURS, 2011; RAMMINGER; ATHAYDE; BRITO, 2013).

No depoimento a seguir, fica nítida a importância do reconhecimento pelo outro; neste caso específico, pela chefia:

[...] aí, a gente montou a biblioteca... a primeira a ser informatizada, foi legal e o diretor reconheceu, fez uma carta agradecendo... foi muito bom! E isso não acontece em outros setores, é só assim: trabalho, trabalho e trabalho... parece assim: você recebe um salário para isso! Concordo, mas um elogio, o reconhecimento moral é muito importante! Te dá um gás, entendeu? Estou sendo reconhecido e está valendo a pena [...] (PA11M35).

Verificou-se ainda a sensação de pertencimento pela utilidade ou pelo estatuto social envolvidos na atividade profissional, como identificado no relato abaixo:

[...] você tem que tentar suavizar, várias vezes... mas nunca fala assim: olha, sumiu o seu documento, olha, você perdeu a viagem, vai ter que voltar outra vez, nunca também virar as costas... meu setor de trabalho me fez entender que eu não pertenço só ao meu setor, eu pertenço à universidade (PD4M7).

E a sensação de pertença fortalecida pela visão da missão da universidade, sendo a função do servidor público enaltecida:

[...] é um impacto direto e importantíssimo na vida do aluno e tem o impacto das empresas que têm como contratar o estagiário de uma instituição reconhecida, que está levando ideias novas... eles não estão só aprendendo na empresa como estão levando conhecimento... então eu acho que é esse tipo de visão que precisa ser expandido para a comunidade como um todo (PC5M2).

A imagem negativa do servidor público, difundida socialmente, como privilegiados que não trabalham, provoca uma espécie de desencantamento entre os entrevistados:

[...] eu acho que existe ainda na sociedade como um todo a imagem negativa daquela pessoa que vai lá pra ficar à toa e recebe o salário ao final do mês... a luta hoje é muito por isso, de reconhecimento que as pessoas comprometidas com o trabalho, elas são a maioria, né, e que a gente precisa ter este reconhecimento por parte do outro, para poder crescer também no nosso serviço, e mostrar como a gente é importante [...] (PC5M2).

Além da imagem negativa do servidor público, identificou-se mal-estar provocado pelo descompasso dentro do próprio ambiente de trabalho, no que diz respeito ao comprometimento diferenciado entre os servidores, como pode ser verificado no depoimento a seguir: 
[...] eu sinto falta de comprometimento dos companheiros e, como eu já passei por lugares diferentes, algumas coisas são características da universidade, entendeu? E assim talvez porque não tenha um chefe direto, alguns companheiros não se dedicam... falta motivação... falta comprometimento mesmo... reclamam, mas não fazem nada! Aí, você vai e muda de setor [...] (PA11M35).

A vontade de oferecer atendimento resolutivo e a preocupação com a formação dos alunos e com a imagem social da universidade contrariam a imagem negativa, difundida socialmente, sobre os servidores, que seriam privilegiados e que não trabalham. O engajamento no trabalho, no entanto, foi identificado como outro potencializador de saúde. O sentimento de envolvimento com a função social de uma universidade pública, de sentir-se útil e de pertencimento possibilita o reconhecimento de si mesmo no processo de trabalho e também do outro, que pode ser o colega, a chefia e até mesmo o usuário.

$\mathrm{O}$ engajamento e o sucesso da ação e da efetividade da política pública dependem, no entanto, do poder de agir (CLOT, 2010), ou seja, deve-se ter como norte no âmbito da saúde do trabalhador a necessidade de potencializar a ação dos trabalhadores. Esta dimensão deve ser reforçada mediante as dificuldades e os limites ressaltados nos depoimentos. O engajamento, portanto, não é suficiente para resolver os problemas dos cidadãos, podendo voltar-se contra os próprios trabalhadores, através do sentimento de impotência, de limitação da ação.

E, nesse sentido, um dos aspectos a ser considerados no processo de significação do trabalho para esta categoria diz respeito à subjetivação da desnecessidade do público (OLIVEIRA, 1999) ou de sua modernização pautada por princípios organizacionais e gerenciais dentro de uma lógica mercantil conflitante com os valores públicos de equidade e justiça. As respostas dadas ao esvaziamento do sentido da ação pública, muitas vezes, não podem ser conduzidas de modo saudável pelo sujeito individual, o que interfere negativamente no sentido do trabalho para o mesmo (ASSUNÇÃO, 2012; COUTINHO; DIOGO; JOAQUIM, 2008; RIBEIRO; MANCEBO, 2013).

\section{Considerações finais}

As categorias identificadas trazem um contorno singular na relação dos servidores em questão com o processo de trabalho no âmbito de uma universidade pública. A imagem social da universidade, construída coletivamente, possibilita um 
sentido pessoal de identidade, com sua nobre missão, a educação, que, por sua vez, propicia o sentimento de pertencimento e engajamento no trabalho. Outras características fortalecem o sentido positivo do trabalho para os assistentes em administração, como o relacionamento com os colegas, as amizades construídas, ser escutado, sua opiniāo fazer diferença, ter qualidade de vida.

Ao contrário da lógica de flexibilização do capitalismo moderno e da economia baseada no princípio de "sem comprometimentos a longo prazo" (SENNETT, 2007), identificam-se no processo de trabalho do setor público, neste caso, de uma universidade pública, a construção de vínculos entre os servidores e a possibilidade de pensar diferente e de expressar tal opinião. Constatou-se, no entanto, que estas experiências não acontecem em todos os ambientes de trabalho e impactam na relação trabalho e saúde.

Relações interpessoais, transparência e participação na gestão, respeito às pessoas e valorização dos esforços dos trabalhadores para resolver os problemas são elementos estratégicos na organização social dos ambientes de trabalho, no sentido de promover benefícios à saúde dos trabalhadores em seu sentido amplo.

O desencantamento provocado pela visão negativa acerca do servidor público, os impedimentos políticos e financeiros criados no âmbito do próprio Estado e/ou as reformas administrativas baseadas numa lógica de mercado afetam a organização do trabalho, que, por sua vez, pressiona e provoca sofrimentos. Os agravos à saúde, num processo de sua vigilância, não devem aparecer como causas naturais, individuais e distantes desta relação. Para isto, a gestão participativa torna-se essencial, pois fortalece o processo educativo no âmbito da universidade para além da sala de aula, através da construção de espaços coletivos, em que todos os integrantes possam colocar suas visões e opiniōes.

Neste estudo, foram enaltecidas a importância da função social de uma universidade pública e a sensação de pertencimento (fazer parte dela). Para potencializar esta identidade com a instituição, cabe a ela o desenvolvimento de ambientes de trabalho saudáveis e estimulantes. A melhoria dos processos de trabalho, através da participação de todos os protagonistas, amplia a saúde institucional e, consequentemente, a qualidade dos serviços prestados, dentro da lógica dos valores públicos de equidade e justiça, num contexto de aprendizado da democracia. ${ }^{2}$ 


\section{Referências}

ANTUNES, R. (Org.). Riqueza e miséria do trabalho no Brasil II. São Paulo: Boitempo, 2013. ARBEX, A.P.S.; SOUZA, K.R.; MENDONCA, A.L.O. Trabalho docente, readaptação e saúde: a experiência dos professores de uma universidade pública. Physis: revista de saúde coletiva. Rio de Janeiro, v. 23, n. 1, p. 263-284, 2013.

ASSUNÇÃO, A.A. A promoção da saúde nos serviços públicos federais. In: ASSUNÇÃO, A.A. (Org.). Promoção e vigilância em saúde: guia para as ações no setor público federal. Belo Horizonte: [s.n.], 2012, p. 8-28.

BALTZER, M. et al. Involvement and structure: a qualitative study of organizational change and sickness absence among women in the public sector in Sweden. BMC public health. London, v. 11, p. 318, May 2011.

BARDIN, L. Análise de conteúdo. Tradução de Luís Antero Reto e Augusto Pinheiro. São Paulo: Ediçōes 70, 2011.

BIANCHESSI, D.L.C.; TITTONI, J. Trabalho, saúde e subjetividade sob o olhar dos trabalhadores administrativo-operacionais de um hospital geral, público e universitário. Physis: revista de saúde coletiva. Rio de Janeiro, v. 19, n. 4, p. 969-988, 2009.

BRASIL. Lei no 11.091, de 12 de janeiro de 2005. Dispóe sobre a estruturação do Plano de Carreira dos Cargos Técnico-Administrativos em Educação, no âmbito das Instituições Federais de Ensino vinculadas ao Ministério da Educação, e dá outras providências. Brasília, DF: Diário Oficial da União, 13 jan. 2005. Seção 1, p. 1.

. Lei no 12.772, de 28 de dezembro de 2012. Dispõe sobre a estruturação do Plano de Carreiras e Cargos de Magistério Federal; sobre a Carreira do Magistério Superior, de que trata a Lei $\mathrm{n}^{\circ}$ 7.596, de 10 de abril de 1987; sobre o Plano de Carreira e Cargos de Magistério do Ensino Básico, Técnico e Tecnológico e sobre o Plano de Carreiras de Magistério do Ensino Básico Federal, de que trata a Lei ${ }^{\circ}$ 11.784, de 22 de setembro de 2008; sobre a contratação de professores substitutos, visitantes e estrangeiros, de que trata a Lei ${ }^{\circ}$ 8.745, de 9 de dezembro de 1993; sobre a remuneração das Carreiras e Planos Especiais do Instituto Nacional de Estudos e Pesquisas Educacionais Anísio Teixeira e do Fundo Nacional de Desenvolvimento da Educação, de que trata a Lei $n^{\circ}$ 11.357, de 19 de outubro de 2006; altera remuneração do Plano de Cargos Técnico-Administrativos em Educação; altera as Leis $\mathrm{n}^{\text {os }} 8.745$, de 9 de dezembro de 1993, 11.784, de 22 de setembro de 2008, 11.091, de 12 de janeiro de 2005, 11.892, de 29 de dezembro de 2008, 11.357, de 19 de outubro de 2006, 11.344, de 8 de setembro de 2006, 12.702, de 7 de agosto de 2012, e 8.168, de 16 de janeiro de 1991; revoga o art. $4^{\circ}$ da Lei ${ }^{\circ} 12.677$, de 25 de junho de 2012; e dá outras providências. Brasília, DF: Diário Oficial da União, 31 dez. 2012. Seção 1, p. 1.

CANGUILHEM, G. O normal e o patológico. Rio de Janeiro: Forense Universitária, 1978. 
CARNEIRO, S.A.M. Saúde do trabalhador público: questão para a gestão de pessoas: a experiência na Prefeitura de São Paulo. Revista do serviço público. Brasília, v. 57, n. 1, p. 23 49, jan./mar. 2006.

CHIAVEGATO FILHO, L.G. Apontamentos da clínica da atividade para compreensão das relaçôes entre saúde e trabalho. In: ARAÚJO, J.N.G.; FERREIRA, M.C.; ALMEIDA, C.P. (Orgs.). Trabalho e saúde: cenários, impasses e alternativas no contexto brasileiro. São Paulo: Opção, 2015, p. 71-92.

CLOT, Y. Trabalho e poder de agir. Belo Horizonte: Fabrefactum, 2010.

CODO, W. A arte de não fazer. O funcionário público faz o que precisa ser feito? In: JACQUES, M.G.; CODO, W. (Orgs.). Saúde mental e trabalho: leituras. Petrópolis: Vozes, 2002, p. 296-308.

COUTINHO, M.C.; DIOGO, M.F.; JOAQUIM, E.P. Sentidos do trabalho e saber tácito: estudo de caso em universidade pública. PSIC: revista de psicologia da Vetor Editora. São Paulo, v. 9, n. 1, p. 99-108, jan./jun. 2008.

DEJOURS, C. O trabalho como enigma. In: LANCMAN, S.; SZNELWAR, L.I. (Orgs.). Christophe Dejours: da psicopatologia à psicodinâmica do trabalho. Tradução de Franck Soudant. Brasília: Paralelo 15; Rio de Janeiro: Fiocruz, 2011, p. 151-166.

DEJOURS, C.; ABDOUCHELI, E.; JAYET, C. Psicodinâmica do trabalho: contribuições da escola dejouriana à análise da relação prazer, sofrimento e trabalho. São Paulo: Atlas, 2014.

ERLANDSSON, L.K. et al. Health factors in the everyday life and work of public sector employees in Sweden. Work. Amsterdam, v. 42, n. 3, p. 321-330, 2012.

FAN, Y. et al. Construction of a new model of job engagement, psychological empowerment and perceived work environment among Chinese registered nurses at four large university hospitals: implications for nurse managers seeking to enhance nursing retention and quality of care. Journal of nursing management. Oxford, v. 24, n. 5, Jul. 2016, p. 646-655.

FERREIRA, M.C. Qualidade de vida no trabalho: Uma abordagem centrada no olhar dos trabalhadores. 2. ed. Brasília: Paralelo 15, 2012.

GOMEZ, C.M. Campo da saúde do trabalhador: trajetória, configuração e transformações. In: GOMEZ, C.M.; MACHADO, J.M.H.; PENA, P.G.L. Saúde do trabalhador na sociedade brasileira contemporânea. Rio de Janeiro: Fiocruz, 2011, p. 23-34.

GONDIM, S.M.G. Grupos focais como técnica de investigação qualitativa: desafios metodológicos. Paidéia. Ribeirão Preto, v. 12, n. 24, p. 149-161, 2002.

HIGGinS, A.; O'HALlORAN, P.; PORTER, S. The Management of Long-Term Sickness Absence in Large Public Sector Healthcare Organisations: A Realist Evaluation Using Mixed Methods. Journal of occupational rehabilitation, Dordrecht, v. 25, n. 3, Sept. 2015, p. 451-470. 
JACKSON FILHO, J.M. Engajamento no trabalho, impedimentos organizacionais e adoecer: a contribuição da Ergonomia da Atividade no setor público brasileiro. Revista brasileira de saúde ocupacional. São Paulo, v. 40, n. 131, p. 98-108, 2015.

LANCMAN, S.; SZNELWAR, L.I. (Orgs.). Christophe Dejours: da psicopatologia à psicodinâmica do trabalho. Tradução de Franck Soudant. Brasília: Paralelo 15; Rio de Janeiro: Fiocruz, 2011.

LAURELL, A.C.; NORIEGA, M. Processo de produção e saúde: o desgaste operário. São Paulo: Hucitec, 1989.

LEÃO, L.H.C.; GOMEZ, C.M. A questão da saúde mental na vigilância em saúde do trabalhador. Ciência \& saúde coletiva. Rio de Janeiro, v. 19, n. 12, p. 4649-4658, dez. 2014. LHUILIER, D. Introdução à psicossociologia do trabalho. Cadernos de psicologia social do trabalho. São Paulo, v. 17, n. spe, p. 5-20, jun. 2014.

LUKÁCS, G. Para uma ontologia do ser social II. Tradução de Carlos Nelson Coutinho, Mario Duayer e Nélio Schneider. São Paulo: Boitempo, 2013.

MACHE, S. et al. Exploring the impact of resilience, self-efficacy, optimism and organizational resources on work engagement. Work (Reading, Mass.). Amsterdam, v. 47, n. 4, p. 491-500, 2014.

MATTOS, R.S.; LUZ, M.T. Quando a perda de sentidos no mundo do trabalho implica dor e sofrimento: um estudo de caso sobre fibromialgia. Physis: revista de saúde coletiva. Rio de Janeiro, v. 22, n. 4, p. 1459-1484, 2012.

MINAYO, M.C.S. O desafio do conhecimento: pesquisa qualitativa em saúde. São Paulo: Hucitec,1992.

MINAYO, M.C.S. (Org.). Pesquisa social: teoria, método e criatividade. Petrópolis: Vozes, 1994.

NASCIMENTO, T.A.C.; OLIVEIRA, S.R. Os sentidos do trabalho no serviço público: uma perspectiva geracional. In: ENCONTRO DA ASSOCIAÇÃO NACIONAL DE PÓSGRADUAÇÃO E PESQUISA EM ADMINISTRAÇÃO, 37, 2013, Rio de Janeiro. Anais... Rio de Janeiro: Anpad, 2013. 16p. Disponível em: <http://www.anpad.org.br/admin/ pdf/2013_EnANPAD_GPR1162.pdf>. Acesso em: 12 abr. 2015.

NEGELISKII, C.; LAUTERT, L. Estresse laboral e capacidade para o trabalho de enfermeiros de um grupo hospitalar. Revista Latino-Americana de enfermagem. Ribeirão Preto, v. 19, n. 3, p. 606-613, jun. 2011.

NOGUEIRA, A.J.F.M.; ROSSINI, V.B. Uma reflexão sobre as relações de trabalho em organizações sem fins lucrativos. Revista de gestão USP. São Paulo, v. 14, n. 1, p. 67-76, jan./ mar. 2007.

NUNES, A.V.L.; LINS, S.L.B. Servidores públicos federais: uma análise do prazer e sofrimento no trabalho. Revista psicologia: organizaçôes e trabalho. Brasília, v. 9, n. 1, p. 51-67, 2009. 
OLIVEIRA, F. Privatização do público, destituição da fala e anulação da política: o totalitarismo neoliberal. In: OLIVEIRA, F.; PAOLI, M.C. (Ed.). Os sentidos da democracia: políticas do dissenso e hegemonia global. Petrópolis: Vozes, 1999, p. 55-81.

RAMMINGER, T.; ATHAYDE, M.R.C.; BRITO, J. Ampliando o diálogo entre trabalhadores e profissionais de pesquisa: alguns métodos de pesquisa-intervenção para o campo da Saúde do Trabalhador. Ciência \& saúde coletiva. Rio de Janeiro, v. 18, n. 11, p. 3191-3202, nov. 2013.

RIBEIRO, C.V.S.; MANCEBO, D. O servidor público no mundo do trabalho do século XXI. Psicologia, Ciência e profissão. Brasília, v. 33, n. 1, p. 192-207, 2013.

ROCHA, A.P.F.; SOUZA, K.R.; TEIXEIRA, L.R. A saúde e o trabalho de médicos de UTI neonatal: um estudo em hospital público no Rio de Janeiro. Physis: revista de saúde coletiva. Rio de Janeiro, v. 25, n. 3, p. 843-862, set. 2015.

SENNETT, R. A corrosão do caráter: as consequências pessoais do trabalho no novo capitalismo. Tradução de M. Santarrita. 12. ed. Rio de Janeiro: Record, 2007.

SILVA, C.O.; RAMMINGER, T. O trabalho como operador de saúde. Ciência \& saúde coletiva. Rio de Janeiro, v. 19, n. 12, p. 4751-4758, dez. 2014.

SILVA, E.M.; MOREIRA, M.C.N. Equipe de saúde: negociações e limites da autonomia, pertencimento e reconhecimento do outro. Ciência \& saúde coletiva. Rio de Janeiro, v. 20, n. 10, p. 3033-3042, out. 2015.

SPILKI, A.; TITTONI, J. O modo-indivíduo no serviço público: descartando ou descartável? Psicologia \& sociedade. Porto Alegre, v. 17, n. 3, p. 67-73, set./dez. 2005.

TITTONI, J. Saúde mental, trabalho e outras reflexôes sobre economia solidária. In: MERLO, A. (Ed.). Saúde e trabalho no Rio Grande do Sul: realidade, pesquisa e intervenção. Porto Alegre: UFRG, 2004, p. 65-93.

TJULIN, A. et al. The social interaction of return to work explored from co-workers experiences. Disability and rehabilitation. Abingdon, v. 33, n. 21-22, p. 1979-1989, 2011.

TRAD, L.A.B. Grupos focais: conceitos, procedimentos e reflexões baseadas em experiências com o uso da técnica em pesquisas de saúde. Physis: revista de saúde coletiva. Rio de Janeiro, v. 19, n. 3, p. 777-796, 2009.

WALLACE, J.E.; LEMAIRE, J.B.; GHALI, W.A. Physician wellness: a missing quality indicator. The Lancet. London, v. 374, n. 9702, p. 1714-1721, Nov. 2009.

\section{Notas}

${ }^{1}$ Informações obtidas junto ao sistema informatizado do setor de Recursos Humanos da instituição estudada.

${ }^{2}$ R.M.O. de Faria e G.A. da Silva foram responsáveis pela concepção do projeto, análise e interpretação dos dados, aprovação da versão final do artigo. I.C.G. Leite foi responsável pela concepção do projeto, revisão crítica do conteúdo intelectual, aprovação da versão final do artigo. 
The meaning of the relationship between work and health for administrative assistants in a public institution of higher education in the state of Minas Gerais

This study aimed to analyze the meaning of the relationship between work and health for administrative assistants in a public institution of higher education in the state of Minas Gerais, Brazil. It is considered a privilege for the worker in the public sector to have steady employment and protection from working conditions that lead to suffering and illness. To study this particular situation, focus groups were adopted for a qualitative exploration, and the information gathered was assessed by content analysis. As outcomes, we highlight the importance of interpersonal relationships, transparency and participation in project management, and the appreciation of workers' efforts to solve problems. A high level of engagement at work was a striking feature that differs markedly from society's widely held view of public servants. Workers felt that their ability to participate in project development was limited and that communication between administrative sectors was lacking to such an extent that they are unable to do their work properly. Such elements should become the focus of oversight in the relationship between work and health, considered strategic in the social organization of work environments in the sense of improving institutional health and the quality of services provided.

> Keywords: occupational health; public sector; working conditions. 